\title{
Verification of the Effectiveness of an SNP Marker in the Cholecystokinin Type A Receptor Gene for Improving Growth Traits in Okumino-kojidori Chickens
}

\author{
Sumiyo Ishikawa ${ }^{1}$, Miho Asano ${ }^{1}$, Kiyoshi Sakai ${ }^{1}$ and Hideaki Takahashi ${ }^{2}$ \\ ${ }^{1}$ Seki Experiment Station, Department of Swine and Poultry Science, \\ Gifu Prefectural Livestock Research Institute, Seki 501-3924, Japan \\ ${ }^{2}$ Institute of Livestock and Grassland Science, NARO, Tsukuba 305-0901, Japan
}

\begin{abstract}
A significant association was reported between a single nucleotide polymorphism (SNP; AB604331, g.420 C>A) in the cholecystokinin type A receptor gene and growth traits in some Japanese slow-growing chickens. Demonstration tests of the genetic improvement effect by comparing the superior allele-A fixed chickens with conventional ones were carried out considering the effect of different seasons on growth traits in other slow-growing chickens. Meat-type Okumino-kojidori chickens from Gifu Prefecture are a three-way cross of Gifu-jidori improved, White Plymouth Rock, and Rhode Island Red breeds. We used a total of 468 meat-type Okumino-kojidori: 264 individuals from a private hatchery as conventional chickens and 204 A-allele fixed individuals from the Gifu Prefectural Livestock Research Institute as improved chickens. We performed fattening experiments over two seasons: summer and winter. In each season, experimental birds of both sexes were hatched on the same day, raised in the same chicken house, and fed the same diet ad libitum for 12 weeks. Body weight was recorded at 3, 6, 9, and 12 weeks of age. SNP genotypes were determined using the mismatch amplification mutation assay. Association between the SNP and growth traits was analyzed using generalized linear models built on sex-based, seasonal, additive, and dominance genetic effects. The observed AA, AC, and CC genotype frequencies in the conventional chickens were $0.158,0.479$, and 0.363 , respectively; body weight at 12 weeks and average daily gain from 3 to 12 weeks was superior for the $\mathrm{A}$ allele compared to the $\mathrm{C}$ allele. The improved chickens were heavier than the conventional ones at 12 weeks. Body weight at 12 weeks in allele-A fixed chickens increased by $3.2 \%$ compared to the conventional chickens. We concluded that g. $420 \mathrm{C}>\mathrm{A}$ is a good selective marker that increases slaughter weight in the meat-type Okumino-kojidori chickens.
\end{abstract}

Key words: chicken, cholecystokinin type A receptor gene, growth traits, Okumino-kojidori chicken, single nucleotide polymorphism

J. Poult. Sci., 57: 107-113, 2020

\section{Introduction}

Since Japan is geologically isolated, chickens in Japan were introduced from overseas at various times. "Jidori" in Japanese originally referred to indigenous chickens thought to be introduced from China more than 2,000 years ago.

Received: June 18, 2019, Accepted: September 10, 2019

Released Online Advance Publication: October 25, 2019

Correspondence: Dr. Hideaki Takahashi, Institute of Livestock and Grassland Science, NARO, Tsukuba 305-0901, Japan.

(E-mail: naoe@affrc.go.jp)

The Journal of Poultry Science is an Open Access journal distributed under the Creative Commons Attribution-NonCommercial-ShareAlike 4.0 International License. To view the details of this license, please visit (https:// creativecommons.org/licenses/by-nc-sa/4.0/).
Gifu-jidori is a Jidori variety native to the Gifu Prefecture, an inland prefecture located in the center of Honshu, Japan. The meat-type Okumino-kojidori is a commercial brand of chicken produced in the Gifu Prefecture. The meat-type Okumino-kojidori chicken is a three-way hybrid chicken produced by crossing Gifu-jidori improved breed cocks, $\mathrm{F}_{1}$ hybrid hens of a White Plymouth Rock cock, and a Rhode Island Red hen. The Gifu-jidori improved breed is a synthetic breed. Four breeds, i.e. Gifu-jidori, Red Cornish, New Hampshire, and Red Rock, were involved in the establishment of the Gifu-jidori improved breed. The Gifu-jidori improved breed has been maintained to be a hereditary percentage of the Gifu-jidori breed by more than $50 \%$. The number of Okumino-kojidori chicks that initially fed in production farms in FY2017 was about 132,000. 
The meat-type Okumino-kojidori chickens are raised to about 12 weeks (wks) of age in both sexes, while broiler chickens are raised for less than 50 days (d). Shortening the rearing period and/or increasing the slaughter weight of the meat-type Okumino-kojidori is important for the benefit of the producers. Rikimaru et al. (2013) first reported a significant association between growth traits and a single nucleotide polymorphism (SNP; AB604331, g.420 C >A) in the 5'-untranslated region of the cholecystokinin type A receptor gene $(C C K A R)$ in a Hinai-dori breed native to the Akita Prefecture in northern Honshu, Japan. Recently, associations between the SNP and growth traits in other brands of chickens, Amakusa Daioh cross (Takahashi et al., 2019) and Miyazaki-jitokko (Horinouchi et al., 2019) chickens have been reported, but reports have not yet validated the effectiveness of genetic improvement by comparing with the conventional chickens. The purpose of this study is to compare genetically improved chickens with conventional ones to test whether the g.420 C>A SNP in CCKAR is useful for improving growth traits in Okumino-kojidori chickens.

\section{Materials and Methods}

\section{Experimental Birds}

The research was performed according to the Guidelines for Proper Conduct of Animal Experiments (Science Council of Japan, 2006), and experimental birds received humane care.

A total of 468 meat-type Okumino-kojidori, including 264 conventional chickens introduced from a local private hatchery (Yamamoto hatchery, Minokamo, Japan) and $204 \mathrm{im}-$ proved chickens that had the fixed A-allele at the g. $420 \mathrm{C}>\mathrm{A}$ SNP and produced at the Seki Experiment Station, Department of Swine and Poultry Science, Gifu Prefectural Livestock Research Institute (Seki, Japan), were used. The fattening experiments were performed by dividing the chickens at the Seki Experiment Station into two seasons: summer from May 23 to August 15, 2018, and winter from November 27, 2018 to February 19, 2019. Experimental birds from each season were hatched on the same day. The chicks were maintained in the same windowless house with forced ventilation but without forced air-cooling systems during the experimental period. Until $3 \mathrm{wks}$, the chicks were housed in a circular area $(1.2 \mathrm{~m}$ in diameter) with $45-\mathrm{cm}$ high chick guards made of zinc coated steel on a concrete floor with a hot water recirculating system for the heat insulation of chicks. After 3 wks, the chicks were raised in concretefloored pens at $9 \mathrm{birds} / \mathrm{m}^{2}$. Sawdust was used as a floor covering and the lighting program in the house was set to a photoperiod of 23-hours light and 1-hour dark throughout the experiment. The luminance above the floor was set to about 8 lux until 3 days, about 6 lux from 4 to 7 days, and 2-4 lux starting at the $8^{\text {th }}$ day. The chicks were fed a starter diet (ME, 3,150 kcal $/ \mathrm{kg}$; CP, 20.5\% (wt/wt)) from 0 to 3 wks and a finisher diet (ME, $3,250 \mathrm{kcal} / \mathrm{kg}$; CP, $18 \%$ ) from 3 to 12 wks. Food and water were provided ad libitum throughout the experiment.

The body weight (BW) of the birds was measured at 3, 6 ,
9, and 12 wks. Average daily gain (ADG) was calculated by dividing weight gain within an interval by the length of the interval in days. The birds were slaughtered at 12 wks.

\section{Genotyping}

Blood was collected from the wing vein and immediately transferred to heparinized tubes. The blood was spotted onto an FTA Card (WB120028; GE Healthcare, Buckinghamshire, UK) and left to dry overnight at room temperature. Extraction of the genomic DNA from the FTA card and genotyping of the g.420 C>A SNP in CCKAR were performed as previously described (Rikimaru et al., 2013).

\section{Statistical Analysis}

Genotype and allele frequencies were calculated using gene counting. SNP-trait association analysis taking into account sex-linked and seasonal effects was conducted in Minitab 18 (Minitab, LLC, State College, PA, USA) using the following generalized linear model (GLM):

$$
y=\mu+C_{g} g+C_{s} s+C_{a} a+C_{d} d+e
$$

where $\mathrm{y}$ is the response variable for each phenotype; $\mu$ is the intercept; the gender effect $(\mathrm{g})$ is a covariate coefficient with $\mathrm{C}_{\mathrm{g}}$ having values of 0 and 1 for female and male, respectively; the seasonal effect (s) is a covariate coefficient with $\mathrm{C}_{\mathrm{s}}$ having values of 0 and 1 for summer and winter, respectively; the additive effect (a) is a covariate coefficient with $\mathrm{C}_{\mathrm{a}}$ having values of 2,1 , and 0 ; the dominance effect (d) is a covariate coefficient with $C_{d}$ having values of 0,1 , and 0 , for genotypes $\mathrm{AA}, \mathrm{AC}$, and $\mathrm{CC}$, respectively; and $\mathrm{e}$ is the residual standard error.

The difference between the two groups was estimated using the following GLM:

$$
y=\mu+C_{g} g+C_{s} s+C_{g r} g r+e
$$

where $\mathrm{y}, \mathrm{g}, \mathrm{s}, \mathrm{C}_{\mathrm{g}}, \mathrm{C}_{\mathrm{s}}$, and e are as described above and the group effect (gr) is a covariate coefficient with $\mathrm{C}_{\mathrm{gr}}$ having values of 0 and 1 for the conventional and improved groups, respectively.

The percentage of haplotype variance explained by the model was calculated as described by Rikimaru et al. (2012), using the following formula:

$$
\text { variance percentage }=100 \times\left(1-F_{\text {var }} / R_{\text {var }}\right)
$$

where $R$ variance $\left(R_{v a r}\right)$ is the residual variance from the reduced model omitting the additive effect but including gender, seasonal, and dominance effects in equation 1; omitting the group effect but including gender and seasonal effects in equation 2. F variance $\left(\mathrm{F}_{\mathrm{var}}\right)$ is the residual variance from the full model in equations 1 and 2.

\section{Results}

Of the conventional birds ( $n=264), 37 \mathrm{AA}, 136 \mathrm{AC}$, and 91 CC birds were detected (Table 1). The genotype frequencies of $\mathrm{AA}, \mathrm{AC}$, and $\mathrm{CC}$ were $0.140,0.515$, and 0.345 , respectively. Allele frequencies of $\mathrm{A}$ and $\mathrm{C}$ were 0.398 and 0.602 , respectively (Table 2 ). In contrast to the conventional birds, the improved birds $(n=204)$ had the A allele fixed (Table 1 and 2).

The effects of the SNP on growth traits in the conventional birds are shown (Table 3). Males were significantly heavier than females from 3 to 12 wks. Winter birds were signifi- 
Table 1. Number of individuals of each genotype, and genotype frequencies in the g.420 C $>$ A SNP in the conventional and improved meat-type Okumino-kojidiri chickens

\begin{tabular}{|c|c|c|c|c|c|c|c|}
\hline \multirow[b]{2}{*}{ Season } & \multirow[b]{2}{*}{ Gender } & \multicolumn{3}{|c|}{ Conventional chickens } & \multicolumn{3}{|c|}{ Improved chickens } \\
\hline & & AA & $\mathrm{AC}$ & $\mathrm{CC}$ & AA & $\mathrm{AC}$ & $\mathrm{CC}$ \\
\hline Summer & Female & 10 & 32 & 20 & 52 & 0 & 0 \\
\hline Summer & Male & 9 & 36 & 34 & 59 & 0 & 0 \\
\hline Winter & Female & 9 & 31 & 15 & 49 & 0 & 0 \\
\hline Winter & Male & 9 & 37 & 22 & 44 & 0 & 0 \\
\hline Total & & 37 & 136 & 91 & 204 & 0 & 0 \\
\hline Genotype $\mathrm{f}$ & cy observed & 0.140 & 0.515 & 0.345 & 1.0 & 0 & 0 \\
\hline
\end{tabular}

Table 2. Allele frequencies observed in the g.420 C $>$ A SNP observed in the conventional and improved meat-type Okumino-kojidiri chickens

\begin{tabular}{|c|c|c|c|c|c|}
\hline \multirow[b]{2}{*}{ Season } & \multirow[b]{2}{*}{ Gender } & \multicolumn{2}{|c|}{ Conventional chickens } & \multicolumn{2}{|c|}{ Improved chickens } \\
\hline & & A & $\mathrm{C}$ & A & $\mathrm{C}$ \\
\hline Summer & Female & 0.419 & 0.581 & 1.0 & 0 \\
\hline Summer & Male & 0.342 & 0.658 & 1.0 & 0 \\
\hline Winter & Female & 0.445 & 0.555 & 1.0 & 0 \\
\hline Winter & Male & 0.404 & 0.596 & 1.0 & 0 \\
\hline \multicolumn{2}{|c|}{ Allele frequency observed } & 0.398 & 0.602 & 1.0 & 0 \\
\hline
\end{tabular}

cantly heavier than the summer birds. As for the additive effect, the significant differences between birds having the A allele and those having the $\mathrm{C}$ allele in $\mathrm{BW}$ at $12 \mathrm{wks}$ show that the A allele significantly increases the slaughter live weight compared to the $\mathrm{C}$ allele. Birds with the A allele had significantly higher ADG than those with the $\mathrm{C}$ allele from 6 to 9 wks and from 3 to 12 wks. As for the dominance effect, significant positive effects on BW at 6 and 9 wks and on ADG in the interval of 3-6 wks were detected.

The effects of the SNP on growth traits between the conventional and improved birds are shown (Table 4). Males were significantly heavier than females from 3 to 12 wks. Winter birds were significantly heavier than summer birds. The improved birds had a significantly heavier BW at 12 wks than the conventional ones, and they also had a higher ADG between 9-12 and 3-12 wks. The percentage increase in $\mathrm{BW}$ in the improved birds compared to the conventional ones at 12 wks were estimated to be about $3.2 \%$.

The effects of the SNP on growth traits in all 468 birds are shown (Table 5). As shown previously, males were significantly heavier than females from 3 to $12 \mathrm{wks}$, and winter birds were significantly heavier than summer birds. As for the additive effect, birds with the A allele are significantly heavier than those with the $\mathrm{C}$ allele based on $\mathrm{BW}$ at 3, 6, 9, and 12 wks. Birds with the A allele had significantly higher ADG than birds with the $\mathrm{C}$ allele between 3-6, 6-9, 9-12, and 3-12 wks. As for the dominance effect, significant positive effects on BW were detected at 6 and 9 wks and on ADG between 3-6 wks.

\section{Discussion}

Cholecystokinin (CCK) is well-known as a gut peptide that inhibits food intake in mammals (Gibbs et al., 1973). Two G-protein-coupled receptors for CCK, CCKAR (Sankaran et al., 1980) and CCK type-B receptor (CCKBR) (Innis and Snyder, 1980), have been reported. CCKAR and CCKBR are predominantly expressed in the gastrointestinal tract and central nervous system, respectively (Wank, 1995). The messenger RNA (mRNA) of CCKAR is mainly distributed in the chicken alimentary tract except for the proventriculus and gizzard, and CCKBR mRNA is predominantly expressed in the brain (Ohkubo et al., 2007).

It is known that exogenously administered CCK octapeptide (CCK-8) via intracerebroventricular (Denbow and Myers, 1982), intravenous (Savory and Gentle, 1980), and intraperitoneal (Covasa and Forbes, 1994) routes transiently depresses food intake in chickens. However, these responses were obtained at high CCK-8 doses. The dosage of CCK in these reports was over 1,000 times higher than the physiological plasma concentration described by Mabayo et al. (1992). Corwin et al. (1991) showed that very low doses of CCKAR antagonist devazepide (DVZ, also called L-364,718 or MK-329), but not large doses of CCKBR antagonist L365,260 , increased food intake in rats. This report is considered to be evidence that endogenous CCK acts on peripheral CCKAR in mammals. CCK-8 and CCK are not believed to cross the blood-brain barrier based on the size of the molecules, but DVZ does cross the blood-brain barrier (Pullen and Hodgson, 1987). It may be that the increased 
Table 3. Effects of g.420 C>A in cholecystokinin type A receptor gene on body weight and average daily gain in the conventional meat-type Okumino-kojidori chickens

\begin{tabular}{lccccc}
\hline \multicolumn{1}{c}{ Traits } & $n$ & intercept & gender & season & additive \\
\hline Body weight (BW, g) & & & & & \\
BW_3wks & 264 & $452.4 \pm 5.3$ & $17.4 \pm 4.8^{* *}$ & $60.1 \pm 4.7^{* *}$ & $5.3 \pm 3.7$ \\
BW_6wks & 264 & $1249.3 \pm 15.7$ & $32.1 \pm 14.0^{*}$ & $330.3 \pm 14.0^{* *}$ & $8.4 \pm 11.1$ \\
BW_9wks & 264 & $1914.6 \pm 24.5$ & $190.4 \pm 21.9^{* *}$ & $730.2 \pm 21.8^{* *}$ & $30.1 \pm 17.3$ \\
BW_12wks & 264 & $2405.7 \pm 33.2$ & $344.6 \pm 29.6^{* *}$ & $1033.4 \pm 29.5^{* *}$ & $49.6 \pm 23.3^{*}$ \\
Average daily gain (ADG, g/day) & & & & \\
ADG_3-6wks & 264 & $37.9 \pm 0.6$ & $0.7 \pm 0.5$ & $12.9 \pm 0.5^{* *}$ & $0.1 \pm 0.4$ \\
ADG_6-9wks & 264 & $31.7 \pm 0.6$ & $7.5 \pm 0.6^{* *}$ & $19.0 \pm 0.6^{* *}$ & $1.0 \pm 0.4^{*}$ \\
ADG_9-12wks & 264 & $23.4 \pm 0.9$ & $7.3 \pm 0.8^{* *}$ & $14.4 \pm 0.8^{* *}$ & $0.9 \pm 0.6$ \\
ADG_3-12wks & 264 & $31.0 \pm 0.5$ & $5.2 \pm 0.4^{* *}$ & $15.4 \pm 0.4^{* *}$ & $0.7 \pm 0.3^{*}$ \\
\hline
\end{tabular}

Table 3. Effects of g.420 $\mathrm{C}>\mathrm{A}$ in cholecystokinin type $\mathrm{A}$ receptor gene on body weight and average daily gain in the conventional meat-type Okumino-kojidori chickens (continued)

\begin{tabular}{lcrrr}
\hline \multicolumn{1}{c}{ Traits } & dominance & \multicolumn{1}{c}{$\mathrm{F}_{\text {var }}$} & $\mathrm{R}_{\text {var }}$ & $\begin{array}{c}\text { Variance } \\
(\%)\end{array}$ \\
\hline Body weight (BW, g) & & & & \\
BW_3wks & $8.2 \pm 5.0$ & 378658 & 381602 & 0.8 \\
BW_6wks & $35.5 \pm 14.7^{*}$ & 3297334 & 3304751 & 0.2 \\
BW_9wks & $45.7 \pm 22.9^{*}$ & 8035992 & 8130530 & 1.2 \\
BW_12wks & $56.7 \pm 31.0$ & 14703859 & 14960450 & 1.7 \\
Average daily gain (ADG, g/day) & & & & \\
ADG_3-6wks & $1.3 \pm 0.5^{*}$ & 4167.6 & 4169.9 & 0.1 \\
ADG_6-9wks & $0.5 \pm 0.6$ & 5241.1 & 5352.2 & 2.1 \\
ADG_9-12wks & $0.5 \pm 0.8$ & 10025.7 & 10115.6 & 0.9 \\
ADG_3-12wks & $0.8 \pm 0.5$ & 3176.9 & 3228.4 & 1.6 \\
\hline
\end{tabular}

**, $P<0.01 ; *, P<0.05$

food intake observed following DVZ administration is due to a central effect rather than the antagonism of endogenous peripheral CCK. Meanwhile, Covasa and Forbes (1994) reported that 1) intraperitoneal DVZ doses ranging from 8 to $32 \mu \mathrm{g} / \mathrm{kg} \mathrm{BW}$ had no effect on food intake in free-feeding chickens two hours after injection, 2) high doses of over 90 $\mu \mathrm{g} / \mathrm{kg} \mathrm{BW}$ of intraperitoneal DVZ increased food intake in free-feeding chickens 90 to 120 minutes after injection, and 3) CCK-8 $(14 \mu \mathrm{g} / \mathrm{kg}$ BW) caused a transient reduction in feeding, and this effect was not blocked by pretreatment with a high dose of over $90 \mu \mathrm{g} / \mathrm{kg}$ BW of intraperitoneal DVZ. Covasa and Forbes (1994) therefore questioned the involvement of endogenous CCK as a satiety agent in chickens, as their findings were in contrast to those of the previous findings of DVZ acting as an effective CCKAR antagonist in rats (Corwin et al., 1991). After all, there is no evidence that CCK acts as a true satiety signal and decreases food intake under physiologically normal conditions in chickens.

Rikimaru et al. (2012) reported significant associations between observed CCKAR haplotypes and growth traits using a resource population crossing low- and high-growth lines of Hinai-dori breed native to the Akita Prefecture in northern Honshu Island, Japan. The authors implied that an SNP (g.420 C>A) in the predicted YY1 binding site (Shrivastava and Calame, 1994) in the $5^{\prime}$-untranslated re- gion of the CCKAR gene may be associated with growth traits. The authors later issued a follow-up report with evidence that the SNP is associated with growth traits (Rikimaru et al., 2013). Shortly after publication of Rikimaru et al. (2013, first published in January 25, 2013), Dunn et al. (2013, first published in February 26, 2013) reported significant associations between CCKAR SNPs and growth traits in a broiler $\times$ White Leghorn intercross population. Dunn et al. (2013) named the g.420 C>A SNP of Rikimaru et al. (2013) as snp.13.786.12116.S.3 and described its segregation with the high- and low-growth haplotype individuals in their population. However, there is a difference between the two research groups in the number of genotypes detected in the $C C K A R$ region, including the promoter, exon, and intron regions. Dunn et al. (2013) detected 37 distinct genotypes, but Rikimaru et al. (2012) detected six distinct genotypes constructed by five haplotypes. The differences in the number of genotypes detected is thought to reflect differences in the resource populations used by the groups. As described above, Dunn et al. (2013) analyzed the crossbred population, but Rikimaru et al. $(2012,2013)$ analyzed the linecross population within a local breed. We think that Rikimaru's group would undoubtedly designate g.420 C>A as a candidate SNP responsible for growth traits since they identified a limited number of haplotypes. On the other hand, 
Table 4. Effects of g.420 $\mathrm{C}>\mathrm{A}$ in cholecystokinin type A receptor gene on body weight and average daily gain in the conventional and improved meat-type Okumino-kojidori chickens

\begin{tabular}{|c|c|c|c|c|c|}
\hline Traits & $\begin{array}{c}\text { Conventional } \\
(n)\end{array}$ & $\begin{array}{l}\text { Improved } \\
\qquad(n)\end{array}$ & Intercept & Gender & Season \\
\hline \multicolumn{6}{|l|}{ Body weight (BW, g) } \\
\hline BW_3wks & 264 & 204 & $451.2 \pm 3.7$ & $42.7 \pm 3.8 * *$ & $50.4 \pm 3.8^{* *}$ \\
\hline BW_6wks & 264 & 204 & $1239.7 \pm 13.4$ & $172.5 \pm 13.5^{* *}$ & $237.0 \pm 13.5^{* *}$ \\
\hline BW_9wks & 264 & 204 & $1922.5 \pm 22.4$ & $421.3 \pm 22.6^{* *}$ & $539.0 \pm 22.6^{* *}$ \\
\hline BW_12wks & 264 & 204 & $2430.4 \pm 29.9$ & $636.6 \pm 30.2^{* *}$ & $778.9 \pm 30.1 * *$ \\
\hline \multicolumn{6}{|c|}{ Average daily gain (ADG, g/day) } \\
\hline ADG_3-6wks & 264 & 204 & $37.5 \pm 0.5$ & $6.2 \pm 0.5^{* *}$ & $8.9 \pm 0.5^{* *}$ \\
\hline ADG_6-9wks & 264 & 204 & $32.5 \pm 0.5$ & $11.9 \pm 0.5^{* *}$ & $14.4 \pm 0.5^{* *}$ \\
\hline ADG_9-12wks & 264 & 204 & $24.2 \pm 0.6$ & $10.2 \pm 0.6^{* *}$ & $11.4 \pm 0.6^{* *}$ \\
\hline ADG_3-12wks & 264 & 204 & $31.4 \pm 0.4$ & $9.4 \pm 0.4 * *$ & $11.6 \pm 0.4 * *$ \\
\hline
\end{tabular}

Table 4. Effects of g.420 C $>\mathrm{A}$ in cholecystokinin type $\mathrm{A}$ receptor gene on body weight and average daily gain in the conventional and improved meat-type Okumino-kojidori chickens (continued)

\begin{tabular}{lcrrr}
\hline \multicolumn{1}{c}{ Traits } & Group & $\mathrm{F}_{\mathrm{var}}$ & $\mathrm{R}_{\mathrm{var}}$ & $\begin{array}{c}\text { Variance } \\
(\%)\end{array}$ \\
\hline Body weight (BW, g) & & & & \\
BW_3wks & $4.7 \pm 3.8$ & 767694 & 770180 & 0.3 \\
BW_6wks & $16.0 \pm 13.6$ & 9848212 & 9877530 & 0.3 \\
BW_9wks & $36.2 \pm 22.7$ & 27494092 & 27644874 & 0.5 \\
BW_12wks & $118.2 \pm 30.3^{* *}$ & 48944685 & 50548065 & 3.2 \\
Average daily gain (ADG, g/day) & & & & \\
ADG_3-6wks & $0.5 \pm 0.5$ & 13938.5 & 13971.9 & 0.2 \\
ADG_6-9wks & $1.0 \pm 0.5$ & 15551.8 & 15658.7 & 0.7 \\
ADG_9-12wks & $3.9 \pm 0.6^{* *}$ & 19389.0 & 21136.8 & 8.3 \\
ADG_3-12wks & $1.8 \pm 0.4^{* *}$ & 10663.5 & 11036.3 & 3.4 \\
\hline
\end{tabular}

**, $P<0.01 ; *, P<0.05$

Rikimaru's group cannot deny Dunn's claim that an SNP located at the downstream region of the CCKAR gene is responsible for growth traits, since DNA sequences in the region have not been determined in the Hinai-dori resource population.

In "Jidori brand chickens" defined by the Japanese Agricultural Standard (Ministry of Agriculture, Forestry and Fisheries of Japan, 1999), there has been a significant association reported between the SNP and growth traits within the conventional Amakusa Daioh Cross (Takahashi et al., 2019) and Miyazaki-jitokko (Horinouchi et al., 2019) chickens, respectively. Takahashi et al. (2019) and Horinouchi et al. (2019) used 144 Amakusa Daioh Cross (72 individuals each of male and female) and 120 male Miyazaki-jitokko chickens, respectively. Previous reports were based on a single fattening experiment of each, but data in this study were obtained from fattening experiments performed in different seasons. So, this report takes into account the seasonal effect on growth traits. Data obtained from previous reports can be compared to the conventional Okuminokojidori chickens shown in Table 3. There were no significant differences between the $\mathrm{A}$ and $\mathrm{C}$ alleles in most intervals during the rearing period in the Amakusa Daioh Cross chickens, but the A allele tended to be superior to the $\mathrm{C}$ allele for ADG traits. The effect of the A allele on ADG traits in the first half of the rearing period in the Miyazaki-jitokko chickens was significantly higher than that in the second half. The tendency that A allele is superior to the $\mathrm{C}$ allele in ADG traits is common in Okumino-kojidori chickens as shown in the Amakusa Daioh Cross and Miyazaki-jitokko chickens, but significant ADG differences between the A and $\mathrm{C}$ alleles were observed in the fourth quarter of the rearing period. These data suggest that g.420 C>A SNP is a good selection marker with high versatility that improves growth performance, even if the timing of the ADG improvement effect varies among the three brands of chickens. Moreover, this study offers a great advantage with the comparison between conventional and SNP marker-selected chickens compared to the previous reports (Takahashi et al., 2019; Horinouchi et al., 2019). We can roughly estimate the number of days saved before slaughtering when the A allele of the g. 420 C $>$ A SNP is fixed in the meat-type Okumino-kojidori chickens. As shown in Table 4, the BW difference of means between the conventional and improved chickens at $12 \mathrm{wks}$ was $118.2 \mathrm{~g}$, and the mean of the ADG intercept between 9-12 wks was $24.2 \mathrm{~g}$. This means that the rearing period is shortened by nearly 5 days.

Geographically, Gifu Prefecture is divided into the Mino 
Table 5. Effects of g.420 C $>\mathrm{A}$ in cholecystokinin type $\mathrm{A}$ receptor gene on body weight and average daily gain in the meat-type Okumino-kojidori chickens in total individuals analyzed

\begin{tabular}{|c|c|c|c|c|c|}
\hline & $n$ & Intercept & Gender & Season & Additive \\
\hline \multicolumn{6}{|c|}{ Body weight $(\mathrm{BW}, \mathrm{g})$} \\
\hline BW_3wks & 468 & $440.6 \pm 5.1$ & $43.4 \pm 3.8^{* *}$ & $49.6 \pm 3.8^{* *}$ & $7.6 \pm 2.5^{*}$ \\
\hline BW_6wks & 468 & $1200.5 \pm 18.1$ & $174.9 \pm 13.4^{* *}$ & $234.1 \pm 13.4^{* *}$ & $26.7 \pm 8.9 * *$ \\
\hline BW_9wks & 468 & $1849.2 \pm 30.2$ & $426.2 \pm 22.4^{* *}$ & $534.0 \pm 22.3^{* *}$ & $54.5 \pm 14.9 * *$ \\
\hline BW_12wks & 468 & $2328.1 \pm 40.3$ & $643.8 \pm 29.8^{* *}$ & $771.4 \pm 29.8^{* *}$ & $105.4 \pm 19.8^{* *}$ \\
\hline \multicolumn{6}{|c|}{ Average daily gain (ADG, g/day) } \\
\hline ADG_3-6wks & 468 & $36.2 \pm 0.7$ & $6.3 \pm 0.5^{* *}$ & $8.8 \pm 0.5^{* *}$ & $0.9 \pm 0.3^{* *}$ \\
\hline ADG_6-9wks & 468 & $30.9 \pm 0.7$ & $12.0 \pm 0.5^{* *}$ & $14.3 \pm 0.5^{* *}$ & $1.3 \pm 0.4 * *$ \\
\hline ADG_9-12wks & 468 & $22.8 \pm 0.8$ & $10.4 \pm 0.6^{* *}$ & $11.3 \pm 0.6^{* *}$ & $2.4 \pm 0.4 * *$ \\
\hline ADG_3-12wks & 468 & $30.0 \pm 0.6$ & $9.5 \pm 0.4 * *$ & $11.5 \pm 0.4^{* *}$ & $1.6 \pm 0.3^{* *}$ \\
\hline
\end{tabular}

Table 5. Effects of g.420 C $>\mathrm{A}$ in cholecystokinin type A receptor gene on body weight and average daily gain in the meat-type Okumino-kojidori chickens in total individuals analyzed (continued)

\begin{tabular}{|c|c|c|c|c|}
\hline & dominance & $\mathrm{F}_{\mathrm{var}}$ & $\mathrm{R}_{\mathrm{var}}$ & $\begin{array}{c}\text { Variance } \\
(\%)\end{array}$ \\
\hline \multicolumn{5}{|c|}{ Body weight (BW, g) } \\
\hline BW_3wks & $8.9 \pm 4.3$ & 752176 & 757925 & 0.8 \\
\hline BW_6wks & $37.5 \pm 15.2 *$ & 9624671 & 9672948 & 0.5 \\
\hline BW_9wks & $58.3 \pm 25.4^{*}$ & 26759435 & 27055204 & 1.1 \\
\hline BW_12wks & $48.9 \pm 33.9$ & 47519947 & 48178629 & 1.4 \\
\hline \multicolumn{5}{|c|}{ Average daily gain (ADG, g/day) } \\
\hline ADG_3-6wks & $1.4 \pm 0.6^{*}$ & 13659.6 & 13706.6 & 0.3 \\
\hline ADG_6-9wks & $1.0 \pm 0.6$ & 15178.8 & 15417.0 & 1.5 \\
\hline ADG_9-12wks & $-0.4 \pm 0.7$ & 19123.8 & 19286.3 & 0.8 \\
\hline ADG_3-12wks & $0.6 \pm 0.5$ & 10375.3 & 10511.6 & 1.3 \\
\hline
\end{tabular}

**, $P<0.01 ; *, P<0.05$

(southern plain) and the Hida (northern mountainous) regions. The Mino region is a famous hot summer location in Japan. Seki City, where the experiments were performed, is located in the central part of the Mino region. The monthly average temperatures in July and August in Seki City in the last 30 years are 26.5 and $27.8^{\circ} \mathrm{C}$, respectively. During the experimental period, the highest recorded temperature in Seki City was $39.6^{\circ} \mathrm{C}$. The observation that summer birds were significantly lighter than winter birds could be due to heat stress in summer even if the birds were raised in a windowless house with forced ventilation systems. The data in this study suggest that the SNP-associated genetic improvement effect on growth traits is expressed even under heat stress conditions.

After adding new evidence described here, we think that there is little doubt that the g. $420 \mathrm{C}>\mathrm{A}$ SNP is a good candidate for marker-assisted selection to improve growth traits with a wide application range in chickens. However, currently there is no explanation as to why g.420 C>A SNP in $C C K A R$ affects growth traits. There have been no data showing that $\mathrm{CCK}$ at physiologically normal concentration ranges is directly involved in food intake. In addition, it is known that the decreased food intake immediately after intraperitoneal CCK-8 administration is a transient phenomenon and food intake soon returns to normal levels after 2 hours
(Covasa and Forbes, 1994). Dunn et al. (2013) administered higher than physiological CCK-8 concentrations via intraperitoneal injection into high-, medium-, and lowgrowth individuals taken from the crossbred population. Even if they observed that high-growth individuals showed minimal reduction of food intake within the 30-minute period after CCK-8 injection, we suspect that the observation reflects physiologically normal eating behavior. The shortterm effect of extremely high dose CCK-8 on food intake does not guarantee its long-term effect on food intake. In contrast, Rikimaru et al. (2014) observed the following phenomena in Hinai-dori individuals raised in a normal fattening environment: 1) the feed conversion ratio between 4 and 10 wks in AA birds was significantly higher than in CC birds, and 2) there were no significant differences in food intake among the three genotypes (AA, AC, and CC) of g.420 C>A SNP. Recently, Rikimaru et al. (2020) reported in the HinaiJidori chicken, a cross between a Hinai-dori sire and Rhode Island Red dam, that 1) food intake within the 30-minute period after feeding of $\mathrm{AA}$ and $\mathrm{AC}$ birds was greater than that of $\mathrm{CC}$ birds; however, there was no significant difference in the daily feed intake among the three genotypes of birds, and 2) birds with AA genotype showed the lowest feed conversion among the three genotypes from 4 to 23 weeks. In summary, Rikimaru et al. $(2014,2020)$ suggest that the 
metabolic efficiency difference affects the growth traits rather than the food intake. Further comprehensive studies of factors affecting metabolic efficiency are needed to explain why the SNP affects growth traits.

In conclusion, we demonstrated the effectiveness of g.420 $\mathrm{C}>\mathrm{A}$ SNP in CCKAR for improving growth traits in meattype Okumino-kojidori chickens. We will use the A-allele of the SNP as a marker to select birds in the parent stock lines and to produce the Okumino-kojidori chickens with high growth performance in the near future. Further study is required to explain why this $C C K A R$ SNP affects growth traits.

\section{Acknowledgments}

This work was financially supported by the Project of the NARO Bio-oriented Technology Research Advancement Institution (the special scheme project on regional developing strategy). We thank the technical support staff of the Seki Experiment Station, Department of Swine and Poultry Science, Gifu Prefectural Livestock Research Institute (Seki, Japan) for their kind assistance.

\section{Conflicts of Interest}

The authors declare no conflicts of interest associated with this manuscript.

\section{References}

Corwin RL, Gibbs J and Smith GP. Increased food intake after type A but not type B cholecystokinin receptor blockade. Physiology \& Behavior, 50: 255-258, 1991.

Covasa M and Forbes JM. Effects of the CCK receptor antagonist MK-329 on food intake in broiler chickens. Pharmacology Biochemistry and Behavior, 48: 479-486. 1994.

Denbow DM and Myers RD. Eating, drinking and temperature responses to intracerebroventricular cholecystokinin in the chick. Peptides, 3: 739-743. 1982.

Dunn IC, Hocking PM, Meddle SL, Wilson PW, Wardle C, Law AS, Bishop A, Hindar C, Robertson GW, Burt DW, Ellison SJL and Morrice DM. Decreased expression of the satiety signal receptor CCKAR is responsible for increased growth and body weight during the domestication of chickens. American Journal of Physiology-Endocrinology and Metabolism, 304: E909E921. 2013.

Gibbs J, Young RC and Smith GP. Cholecystokinin decreases food intake in rats. Journal of Comparative and Physiological Psychology, 84: 488-495. 1973.

Horinouchi S, Nakayama $\mathrm{H}$ and Takahashi $\mathrm{H}$. Effect of a single nucleotide polymorphism in the cholecystokinin type A receptor gene on growth traits of the Miyazaki Jitokko chicken. Journal of Poultry Science, 56: 96-100. 2019.

Innis RB and Snyder SH. Distinct cholecystokinin receptors in brain and pancreas. Proceedings of the National Academy of Sciences of the United States of America, 77: 6917-6921. 1980.
Mabayo RT, Furuse M, Yang S and Okumura J. Medium-chain triacylglycerols enhance release of cholecystokinin in chicks. Journal of Nutrition, 122: 1702-1705. 1992.

Ministry of Agriculture, Forestry and Fisheries of Japan. Japanese Agricultural Standard (JAS): Specific JAS Standards for naturally grown chicken. Ministry of Agriculture, Forestry and Fisheries of Japan, Tokyo. http://www.maff.go.jp/j/jas/jas_kikaku/ pdf/kikaku_jidori_150821.pdf. Accessed on May 17, 2019. (in Japanese)

Ohkubo T, Shamoto K and Ogino T. Structure and tissue distribution of cholecystokinin-1 receptor in chicken. Journal of Poultry Science, 44: 98-104. 2007.

Pullen RGL and Hodgson OJ. Penetration of diazepam and the nonpeptide CCK antagonist, L364,718 into rat brain. Journal of Pharmacy and Pharmacology, 39: 863-864. 1987.

Rikimaru K, Komatsu M, Suzuki K, Uemoto Y, Takeda H and Takahashi H. Association between cholecystokinin type A receptor haplotypes and growth traits in Japanese Hinai-dori crossbred chickens. Molecular Biology Reports, 39: 44794484. 2012.

Rikimaru K, Takeda H, Uemoto Y, Komatsu M, Takahashi D, Suzuki K and Takahashi H. Effect of a single-nucleotide polymorphism in the cholecystokinin type A receptor gene on growth traits in the Hinai-dori chicken breed. Journal of Poultry Science, 50: 206-211. 2013.

Rikimaru K, Takeda H, Ohkubo T, Takahashi D, Komatsu M and Takahashi H. The A allele of the cholecystokinin type A receptor g.420 C>A polymorphism improves the growth rate of the Hinai-dori breed. Japanese Journal of Poultry Science, 51: J43-J48. 2014. (in Japanese)

Rikimaru K, Sato Y, Ito Y, Fukuda S, Sasaki S and Takahashi H. Is a single nucleotide Polymorphism marker in the cholecystokinin A receptor gene practically suitable for improving the growth traits of Hinai-jidori chickens? Journal of Poultry Science, 57: 99-106. 2020.

Sankaran H, Goldfine ID, Deveney CW, Wong KY and Williams JA. Binding of cholecystokinin to high affinity receptors on isolated rat pancreatic acini. Journal of Biological Chemistry, 255: 1849-1853. 1980.

Savory CJ and Gentle MJ. Intravenous injections of cholecystokinin and caerulein suppress food intake in domestic fowls. Experientia, 36: 1191-1192. 1980.

Science Council of Japan. Guidelines for proper conduct of animal experiments. http://www.scj.go.jp/ja/info/kohyo/pdf/kohyo-20k16-2e.pdf. Accessed on May 20, 2019.

Shrivastava A and Calame K. An analysis of genes regulated by the multi-functional transcriptional regulator Yin Yang-1. Nucleic Acids Research, 22: 5151-5155. 1994.

Takahashi H, Katayama M, Michishita K and Yamashita H. The A allele of the cholecystokinin type A receptor g. $420 \mathrm{C}>\mathrm{A}$ polymorphism improves the growth traits of the Amakusa Daioh Cross chicken. Journal of Poultry Science, 56: 91-95. 2019.

Wank SA. Cholecystokinin receptors. American Journal of PhysiologyGastrointestinal and Liver Physiology, 269: G628-G646. 1995. 